\title{
Numerical Implementation and Calibration of a Hysteretic Model for Cyclic Response of End-Plate Beam-to-Column Steel Joints under Arbitrary Cyclic Loading
}

\author{
Pedro Nogueiro $^{1 *}$, Luís Simões da Silva ${ }^{2}$, Rita Bento ${ }^{3}$ \\ ${ }^{1}$ Polytechnic Institute of Bragança,Bragança, Portugal \\ ${ }^{2}$ Department of Civil Engineering, University of Coimbra - Polo II, Pinhal de Marrocos, Coimbra Portugal \\ ${ }^{3}$ Department of Civil Engineering, Instituto Superior Técnico, Av. Rovisco Pais, Lisbon, Portugal
}

Email: nogueiro@ipb.pt, luisss@dec.uc.pt, rbento@civil.ist.utl.pt,

\begin{abstract}
This work presents the implementation and calibration of Modified Richard-Abbott model for cyclic response of four end-plate beam-to-column steel joints under arbitrary cyclic loading. The joints parameters are found and the comparison between the analytical hysteretic results and the experimental hysteretic results is made, as well as the hysteretic energy dissipated evaluated for each cycle and obtained for both type of analyses.
\end{abstract}

Key words: Implementation, Calibration, Hysteretic model, Hysteretic energy dissipation, Steel Joint.

\section{INTRODUCTION}

The recent publication of part 1-1 of Eurocode 8 [1] provides some rules for the design and detailing of joints subjected to seismic loading. In particular, for moment resisting frames, it is specifically allowed to use dissipative semi-rigid and/or partial strength connections, provided that all of the following requirements are verified:

a) the connections have a rotation capacity consistent with the global deformations;

b) members framing into the connections are demonstrated to be stable at the ultimate limit state (ULS);

c) the effect of connection deformation on global drift is taken into account using nonlinear static (pushover) global analysis or non-linear dynamic time history analysis.

Additionally, the connection design should be such that the rotation capacity of the plastic hinge region is not less than 35 mrad for structures of high ductility class DCH and 25 mrad for structures of medium ductility class DCM with the behaviour coefficient $q$ greater than $2(q>2)$ [1]. The rotation capacity of the plastic hinge region should be ensured under cyclic loading without degradation of strength and stiffness greater than 20\%. This requirement is valid independently of the intended location of the dissipative zones. The column web panel shear deformation should not contribute for more than $30 \%$ of the plastic rotation capability. Finally, the adequacy of design should be supported by experimental evidence whereby strength and ductility of members and their connections under cyclic loading should be supported by experimental evidence, in order to conform to the specific requirements defined above. This applies to partial and full strength connections in or adjacent to dissipative zones.

It is clear that Eurocode 8 opens the way for the application of analytical procedures to justify connection design options, while still requiring experimental evidence to support the various options. In contrast, North American practice, following the Kobe and Northridge earthquakes, was directed in a pragmatic way 
towards establishing standard joints that would be pre-qualified for seismic resistance [2]. This approach, although less versatile, would certainly be of interest for the European industry, especially if it could overcome uncertainties that would require experimental validation. Unfortunately, North American design practice and usual ranges of steel sections are clearly different from European design practice. Thus, the benefits of the SAC research programme [3] concerning pre-qualified moment resisting joints are not directly applicable.

To follow the European analytical approach, two mathematical formulas have historically provided the basis for most of the models that have been proposed in the literature: Ramberg-Osgood type mathematical expressions [4], that usually express strain (generalized displacement) as a non-linear function of stress (generalized force) and Richard-Abbott type mathematical expressions [5], that usually relate generalized force (stress) with generalized displacement (strain).

Ramberg-Osgood based mathematical models were first used by Popov and Pinkey [6] to model hysteresis loops of non-slip specimens and later applied to model the skew symmetric moment-rotation hysteretic behaviour of connections made by direct welding of flanges with or without connection plate (Popov and Bertero) [7]. Mazzolani [8] developed a comprehensive model based on the Ramberg-Osgood expressions that was able to simulate the pinching effect, later modified by Simões et al. [9] to allow for pinching to start in the unloading zone. It is noted that models based on the Ramberg-Osgood expressions present the disadvantage of expressing strain as a function of stress, which clearly complicates its integration in displacement-based finite element codes (that constitute the majority of the available applications) or the direct application for the calibration and evaluation of test results, almost always carried out under displacement-control once they reach the non-linear stage.

The Richard-Abbott expression was first applied to the cyclic behaviour of joints by De Martino et al. [10]. Unfortunately, that implementation was not able to simulate the pinching effect (Simões et al.) [9]. Subsequently, Della Corte et al. [11] proposed a new model, also based on the Richard-Abbott expressions, that was capable of overcoming this limitation and to model the pinching effect, as well as strength and stiffness deterioration and the hardening effects.

It is the objective of this paper to report the numerical implementation and calibration of the Modified Richard-Abbott model of four end-plate beam-to-column steel joints under arbitrary cyclic loading.

\section{EXPERIMENTAL PROGRAMME}

The experimental programme, herin presented, corresponds to the first part of a wider study and comprises six external double end-plate joints. It is divided into two groups, whereby the column section size is varied, as can be observed in table 1 . End plates, $18 \mathrm{~mm}$ thick, were connected to the beam-ends by full strength $45^{\circ}$ continuous fillet welds, shop welded in a down and up position. A manual metal arc welding procedure was used, with Autal Gold 70S electrodes. Hand tightened, full-threaded M24, 10.9 grade, in 26 mm diameter drilled holes were employed in all joints. All the material is steel grade S355. Figures 1 and 2 show the connection details.

Each group includes a first test with the loading applied monotonically, and two more tests with cyclic loading. The cyclic loading strategy consists of two distinct cyclic histories (i) increasing cyclic amplitude in the elastic range and constant amplitude loading at approximately three times the yield rotation $\left(\phi_{\mathrm{y}} \times 3\right)$ and (ii) increasing cyclic amplitude in the elastic range and constant amplitude loading at approximately $\phi_{\mathrm{y}} \times 6$. After twenty cycles, the amplitude loading was increased by 2.5 mrad. The tests were carried out with displacement control, with constant speed of $0.02 \mathrm{~mm} / \mathrm{sec}$ for the monotonic tests, $0.4 \mathrm{~mm} / \mathrm{sec}$ for the first cyclic tests and $0.2 \mathrm{~mm} / \mathrm{sec}$ for the second cyclic tests. 
Table 1: Bolted Beam-To-Column extended end-plate joints test programme.

\begin{tabular}{ccccccc}
\hline \multirow{2}{*}{ Group 1 (J1) } & $\begin{array}{c}\text { Beam } \\
\text { IPE }\end{array}$ & $\begin{array}{c}\text { Column } \\
\text { HEA }\end{array}$ & $\begin{array}{c}\text { steel } \\
\text { S355 }\end{array}$ & type & Bending & \multirow{2}{*}{ Axial } \\
\hline Test J-1.1 & 360 & 320 & “ & Monotonic & M- & - \\
Test J-1.2 & 360 & 320 & “ & Cyclic & M-/M+ & - \\
Test J-1.3 & 360 & 320 & “ & Cyclic & M-/M+ & - \\
\hline Group 3 (J3) & IPE & HEB & S355 & type & Bending & Axial \\
\hline Test J-3.1 & 360 & 320 & “ & Monotonic & M- & - \\
Test J-3.2 & 360 & 320 & “ & Cyclic & M-/M+ & - \\
Test J-3.3 & 360 & 320 & “ & Cyclic & M-/M+ & - \\
\hline
\end{tabular}
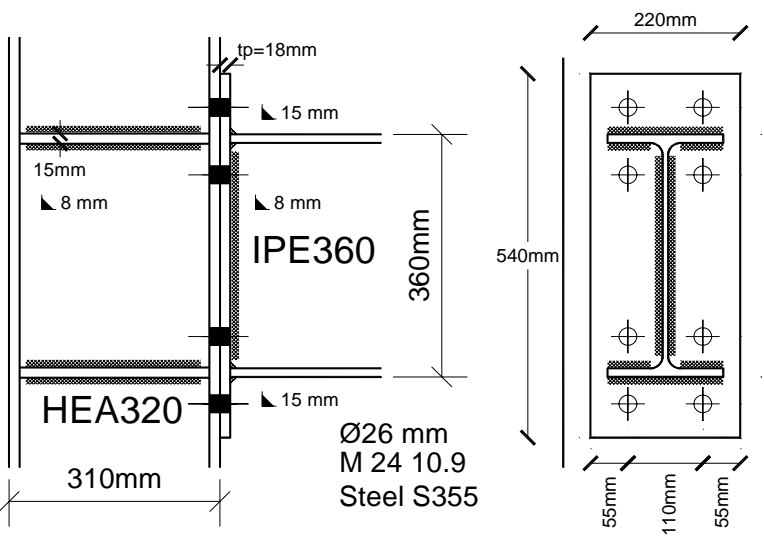

(a)

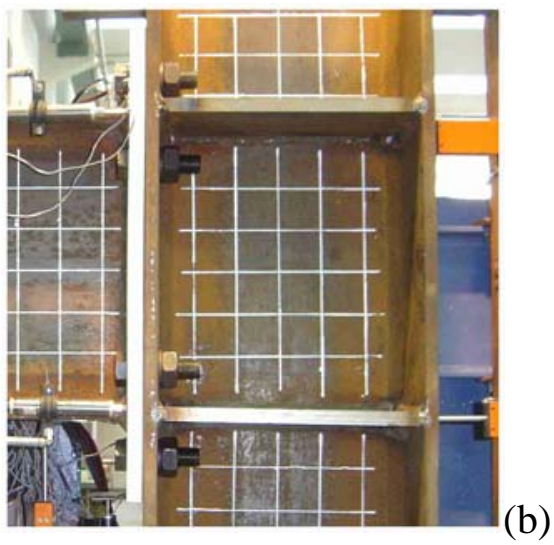

Figure 1: Detail of the joint for the Group 1; (a) Geometrical and (b) Illustration.

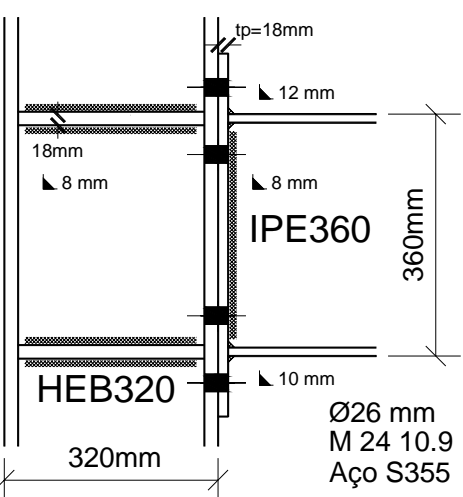

Figure 2: Detail of the joint for the Group 3;

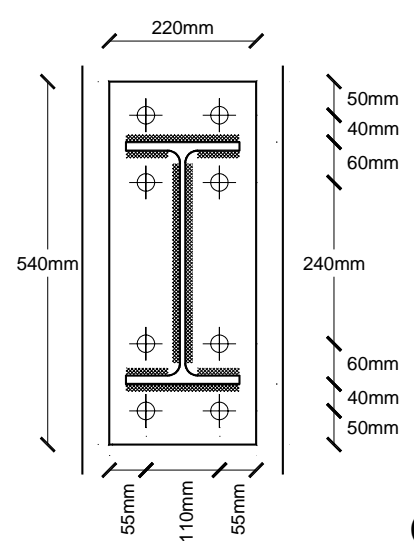

(a)

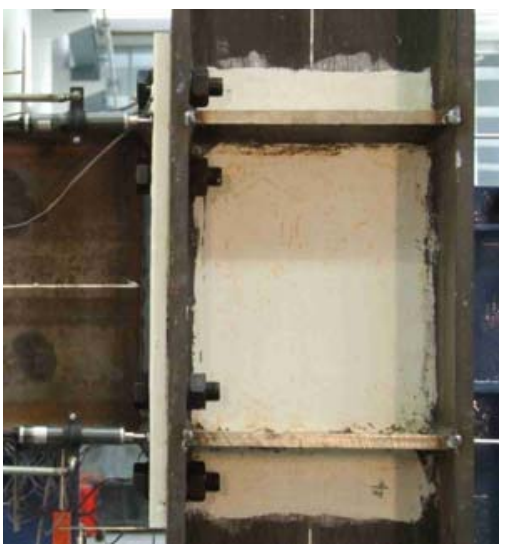

(b)

The choice of steel members and connection details result from the design of the Cardington building using the Eurocodes EC0/EC1/EC3/EC4 [12] [13] [14] [15] and EC8 [1], with an alternative choice of columns (HEA and HEB) to match the seismic design criteria.

\section{EXPERIMENTAL RESULTS}

\section{Monotonic tests}

The following figures, figures $3 \mathrm{a}$ and $3 \mathrm{~b}$, present the results of the monotonic tests. Besides establishing the failure modes of the joints, these tests help to establish the basic mechanical joint properties, like the initial stiffness, the strength, the yield rotation and the ultimate rotation. In addition, this information is very important to establish the cyclic loading strategy.

Theoretically, according the EC3 [14], joint J-1.1 presents an initial stiffness equal to $61694 \mathrm{kNm} / \mathrm{rad}$, a moment resistance of $272.71 \mathrm{kNm}$ and it is expected to fail from the column web panel in shear. As can be observed in figure 3a, an initial stiffness equal to approximately $69500 \mathrm{kNm} / \mathrm{rad}$ was obtained and a 
resistance approximately of $288 \mathrm{kNm}$, and a ultimate moment resistance of $419 \mathrm{kNm}$ were reached. The observed yield rotation was $4.14 \mathrm{mrad}$ and the ultimate rotation approximately $70 \mathrm{mrad}$. The observed experimental failure mode was the column web panel in shear, although the model was further loaded up to end-plate failure, which results in a large deformation of the model, in excess of $100 \mathrm{mrad}$. The column web panel and the extended end-plate were responsible for the majority of the energy dissipation.

Similarly, according to EC3 [14], joint J-3.1 presents an initial stiffness of $75400 \mathrm{kNm} / \mathrm{rad}$, a moment resistance of $287.83 \mathrm{kNm}$ and it is expected to fail from the column web panel in shear. As can be observed in figure 3b, an initial stiffness equal to approximately $100000 \mathrm{kNm} / \mathrm{rad}$ was obtained and a resistance approximately of $336 \mathrm{kNm}$, and a ultimate moment resistance of $477 \mathrm{kNm}$ were reached. The observed yield rotation was $3.37 \mathrm{mrad}$ and the ultimate rotation approximately $47 \mathrm{mrad}$. The observed experimental failure mode was the column web panel in shear. No bolt failure was observed for both tests.
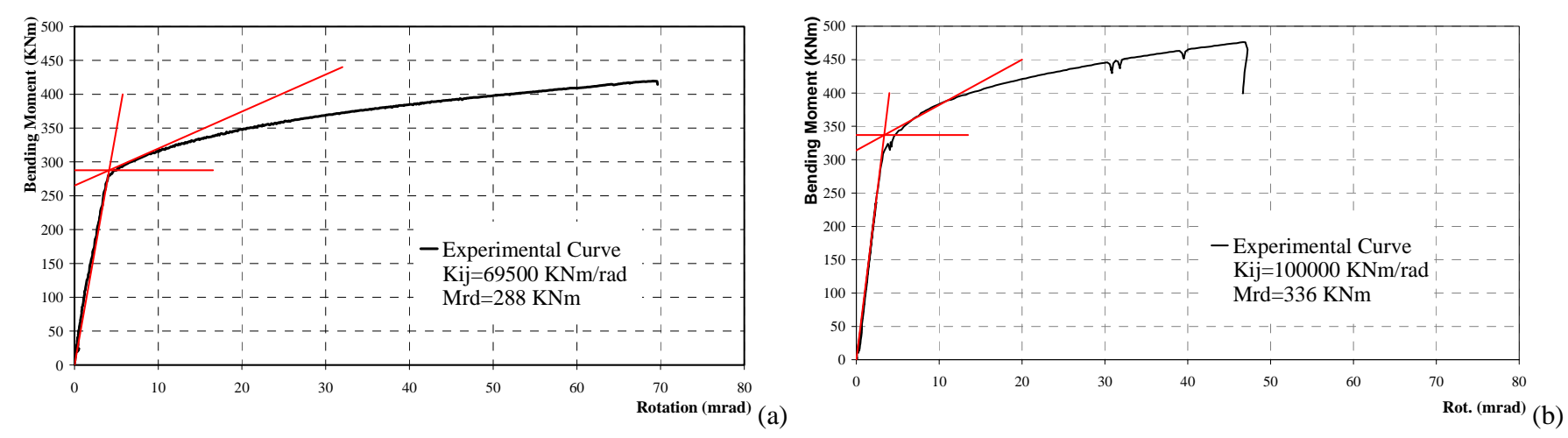

Figure 3: Experimental monotonic curve; (a) J-1.1 test and (b) J-3.1 test.

Both joints exhibit high strength and stiffness. It is important to note that, for test J-1.1, the nominal plastic strength of the connected beam (IPE360) is $361.75 \mathrm{kNm}$, giving a degree of partial strength of 0.80 . It is noted that the real degree of partial strength is lower, given that the actual yield stress of the steel beam, is significantly higher (tensile coupon tests are being carried out at this stage). This behaviour was justified, rather than by the steel grade, by the transversal web column stiffeners and by the extended end-plate geometry, thickness and distance of the bolts.

\section{Cyclic tests}

Figures $4 \mathrm{a}$ and $4 \mathrm{~b}$ present the hysteretic Moment -Rotation $(M-\varnothing)$ experimental curves, respectively for $\mathrm{J}-1.2$ and J-1.3 cyclic tests. The chosen load strategy, had the main purpose to study the oligocyclic fatigue that is typical of steel behaviour. Stable hysteretic curves for both tests with a great energy dissipation can be observed. The first cyclic test (J-1.2), which had lower amplitudes, reached 82 cycles against 22 reached with the J-1.3 test, as can be observed in figures 7 and 8 , and 9. The mode of failure observed for these two tests was the same, cracking in the extended end plate at the interface between the weld and the base material. Most of the energy was dissipated by the column web panel (80\%) and by the extended end-plate.

From these hysteretic curves, it can be concluded that these joints do not exhibit any slippage, do not have strength deterioration and the deterioration of stiffness is low.

Figures $5 \mathrm{a}$ and $5 \mathrm{~b}$ present the hysteretic $M-\varnothing$ experimental curves, respectively for J-3.2 and J-3.3 tests. The cyclic J-3.2 test, reached failure after 26 cycles on the extended end-plate as can be seen further on in figure $11 \mathrm{a}$.

The J-3.3 model endured 13 cycles only (figure 11b), less than the ones reached with the J-1.3 test. The same conclusion is valid for tests J-1.2 and J-3.2. This is justified by the column section size, as the majority of the joint deformation occurring in the column web panel between the transversal stiffeners. For a stronger column, the extended end-plate is relatively weaker, and failure will occur at an earlier stage. Final failure 
for the J-3.3 model occurred at the HAZ (Heat Affected Zone) on the beam side, for a value of the maximum moment of $429.7 \mathrm{kNm}$.

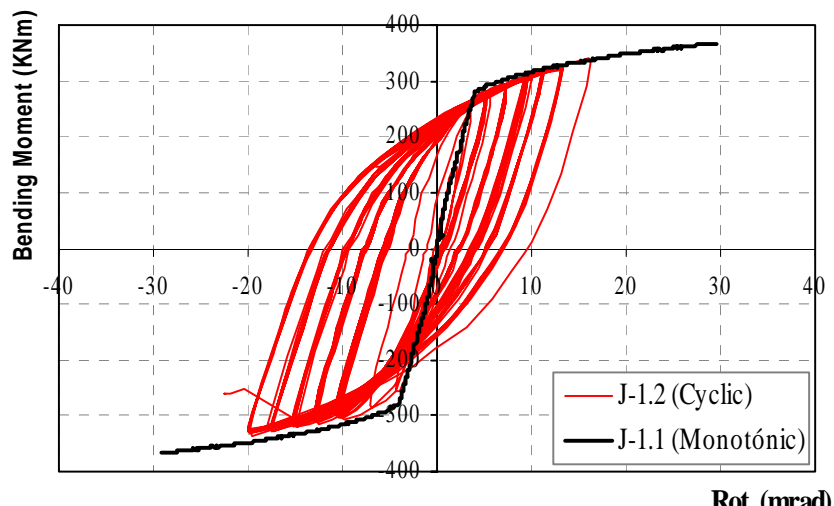

Rot. (mrad) a)

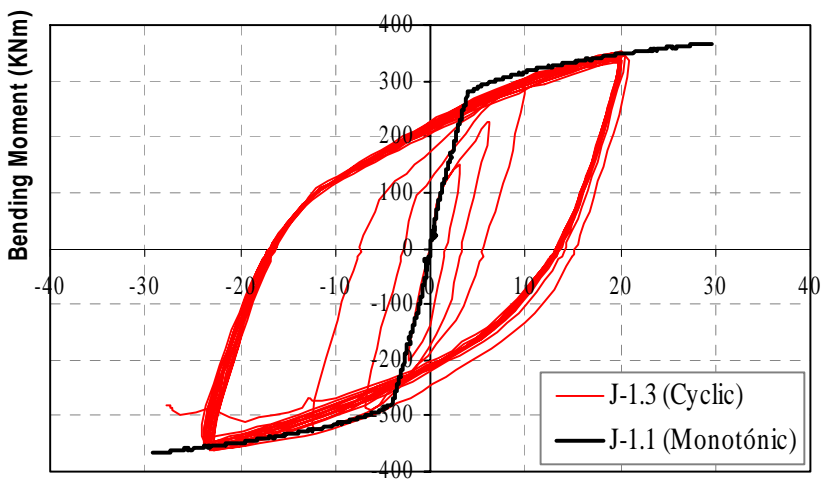

Rot. (mrad)

Figure 4: Hysteretic $M-\varnothing$ experimental curves; (a) J-1.2 test and (b) J-1.3 test.

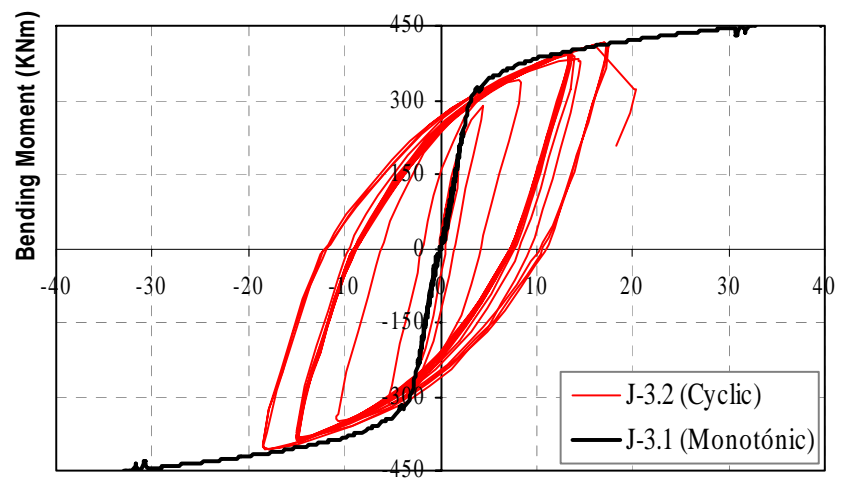

Rot. (mrad)

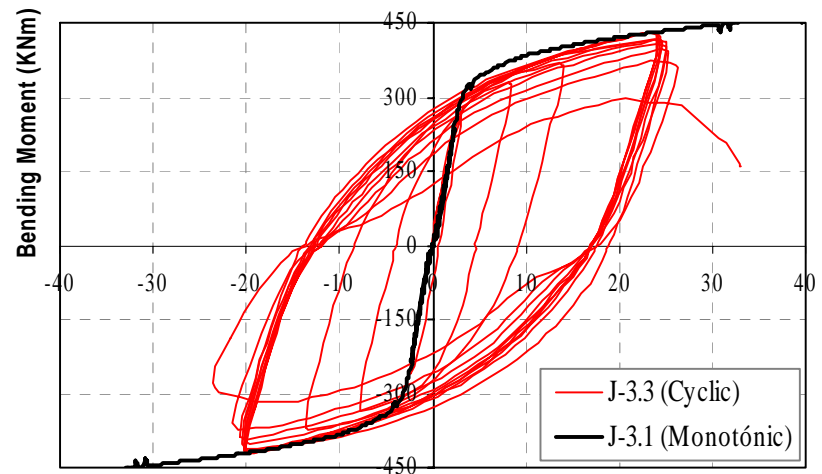

Rot. (mrad)

a)

Figure 5: Hysteretic $M-\varnothing$ experimental curves; (a) J-3.2 test and (b) J-3.3 test.

\section{APPLICATION OF THE RICHARD-ABBOTT MODIFIED METHOD}

\section{Model Description}

The modified Richard-Abbott model was developed by Della Corte et al. [10], to include pinching. According to this model, the loading curve for a generic branch of the moment-rotation curve of a joint is given by the following equation:

$$
M=M_{n}-\frac{\left(k_{a}-k_{p a}\right) \cdot\left(\phi_{n}-\phi\right)}{\left[1+\left|\frac{\left(k_{a}-k_{p a}\right) \cdot\left(\phi_{n}-\phi\right)}{M_{0 a}}\right|^{N}\right]^{1 / N}}-k_{p a} \cdot\left(\phi_{n}-\phi\right)
$$

The complete explanation of the expression (1) can be found in Nogueiro et al [16]. The numerical implementation of the hysteretic model described above was carried out using the Delphi [17] development platform. A six degree-of-freedom spring element was implemented in the structural analysis software SeismoStruct [18]. The implementation comprised two major parts. The first consists of the management of the hysteretic cycles, where a clear distinction between positive and negative moment must be made because of possible asymmetry of joint response under hogging or sagging bending. The second part of the implementation relates to the development of the code for each cycle. 
In total, 30 parameters have to be defined for this model, fifteen for the ascending branches (subscript $a$ ) and fifteen for the descending branches (subscript $d$ ): $K_{a}$ (and $K_{d}$ ) is the initial stiffness, $M_{a}$ (and $M_{d}$ ) is the moment resistance, $K_{p a}$ (and $K_{p d}$ ) is the post limit stiffness, $n_{a}$ (and $n_{d}$ ) is the shape parameter, all these for the upper bound curve $K_{a p}$ (and $K_{d p}$ ) is the initial stiffness, $M_{a p}$ (and $M_{d p}$ ) is the strength, $K_{p a p}$ (and $K_{p d p}$ ) is the post limit stiffness, $n_{a p}$ (and $n_{d p}$ ) is the shape parameter, all these for the lower bound curve, $t_{1 a}$ and $t_{2 a}$ (and $t_{1 d}$ and $t_{2 d}$ ) are the two parameters related to the pinching, $C_{a}$ (and $C_{d}$ ) is the calibration parameter related to the pinching, normally equal to $1, i_{K a}$ (and $i_{K d}$ ) is the calibration coefficient related to the stiffness damage rate, $i_{M a}$ (and $i_{M d}$ ) is the calibration coefficient related to the strength damage rate, $H_{a}$ (and $H_{d}$ ) is the calibration coefficient that defines the level of isotropic hardening and $E_{\max a}$ (and $E_{\operatorname{maxd}}$ ) is the maximum value of deformation.

The model was prepared to work with any kind of loads, especially for the seismic action where loading and unloading branches can be either large or small.

\section{Implementation of the model to the cyclic tests}

This section presents the results of the implementation and calibration of the modified Richard-Abbott model applied to those experimental tests previously presented. The first step is to find the 30 model parameters which allow to simulate the experimental hysteretic curves. For a joint without pinching, the seven parameters in the middle of table 2 are equal to zero. Considering, also, that there is no deterioration of strength and hardening 4 further parameters are equal to zero, remaining the initial four parameters which result from the corresponding monotonic tests. From the cyclic tests deterioration of stiffness can be observed. The last parameter, the maximum value of deformation, is always taken equal to 0.1 .

Table 2: Joints parameters.

\begin{tabular}{|c|c|c|c|c|c|c|c|c|c|c|c|c|c|c|c|}
\hline Tests & $\begin{array}{c}\mathrm{K}_{\mathrm{a}} \\
\mathrm{KNm} / \mathrm{rad}\end{array}$ & $\begin{array}{c}\mathrm{M}_{\mathrm{a}} \\
\mathrm{KNm}\end{array}$ & $\underset{\mathrm{KNm} / \mathrm{rad}}{\mathrm{K}_{\mathrm{pa}}}$ & $\mathrm{n}_{\mathrm{a}}$ & $\begin{array}{c}\mathrm{K}_{\mathrm{ap}} \\
\mathrm{KNm} / \mathrm{rad}\end{array}$ & $\begin{array}{l}\mathrm{M}_{\mathrm{ap}} \\
\mathrm{KNm}\end{array}$ & $\begin{array}{c}\mathrm{K}_{\text {pap }} \\
\text { KNm/rad }\end{array}$ & $\mathrm{n}_{\mathrm{ap}}$ & $\mathrm{t}_{1 \mathrm{a}}$ & $t_{2 a}$ & $\mathrm{C}_{\mathrm{a}}$ & $\mathrm{i}_{\mathrm{Ka}}$ & $\mathrm{i}_{\mathrm{Ma}}$ & $\mathrm{H}_{\mathrm{a}}$ & $\begin{array}{c}E_{\operatorname{maxa}} \\
\text { rad }\end{array}$ \\
\hline $\mathrm{J}-1.2 / \mathrm{J}-1.3$ & 69500 & 288 & 5500 & 1 & 0 & 0 & 0 & 0 & 0 & 0 & 0 & 2 & 0 & 0 & 0.1 \\
\hline \multirow[t]{2}{*}{$\mathrm{J}-3.2 / \mathrm{J}-3.3$} & 100000 & 336 & 6500 & 1 & 0 & 0 & 0 & 0 & 0 & 0 & 0 & 10 & 0 & 0 & 0.1 \\
\hline & $\underset{\mathrm{KNm} / \mathrm{rad}}{\mathrm{K}_{\mathrm{d}}}$ & $\begin{array}{c}\mathrm{M}_{\mathrm{d}} \\
\mathrm{KNm}\end{array}$ & $\begin{array}{c}\mathrm{K}_{\mathrm{pd}} \\
\mathrm{KNm} / \mathrm{rad}\end{array}$ & $\mathrm{n}_{\mathrm{d}}$ & $\begin{array}{c}\mathrm{K}_{\mathrm{dp}} \\
\mathrm{KNm} / \mathrm{rad}\end{array}$ & $\begin{array}{l}\mathrm{M}_{\mathrm{dp}} \\
\mathrm{KNm}\end{array}$ & $\begin{array}{c}\mathrm{K}_{\mathrm{pdp}} \\
\mathrm{KNm} / \mathrm{rad}\end{array}$ & $\mathrm{n}_{\mathrm{dp}}$ & $\mathrm{t}_{1 \mathrm{~d}}$ & $t_{2 d}$ & $\mathrm{C}_{\mathrm{d}}$ & $\mathrm{i}_{\mathrm{Kd}}$ & $\mathrm{i}_{\mathrm{Md}}$ & $\mathrm{H}_{\mathrm{d}}$ & $\begin{array}{c}E_{\operatorname{maxd}} \\
\operatorname{rad}\end{array}$ \\
\hline $\mathrm{J}-1.2 / \mathrm{J}-1.3$ & 69500 & 288 & 5500 & 1 & 0 & 0 & 0 & 0 & 0 & 0 & 0 & 2 & 0 & 0 & 0.1 \\
\hline J-3.2/J-3.3 & 100000 & 336 & 6500 & 1 & 0 & 0 & 0 & 0 & 0 & 0 & 0 & 10 & 0 & 0 & 0.1 \\
\hline
\end{tabular}

\section{COMPARISON BETWEEN ANALYTICAL AND EXPERIMENTAL RESULTS}

Figures $6 \mathrm{a}$ and $6 \mathrm{~b}$ present the experimental and analytical curves for tests $\mathrm{J}-1.2$ and J-1.3, respectively. A good agreement between the experimental and the analytical curves is observed.

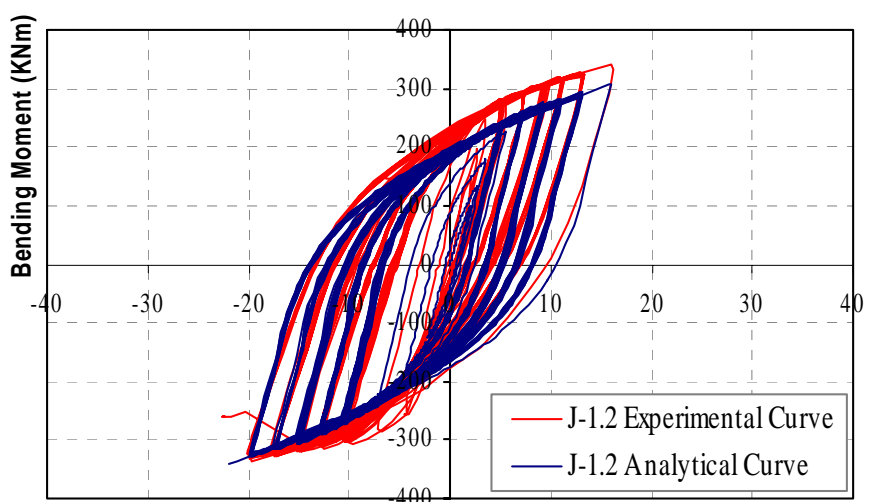

Rot. (mrad)

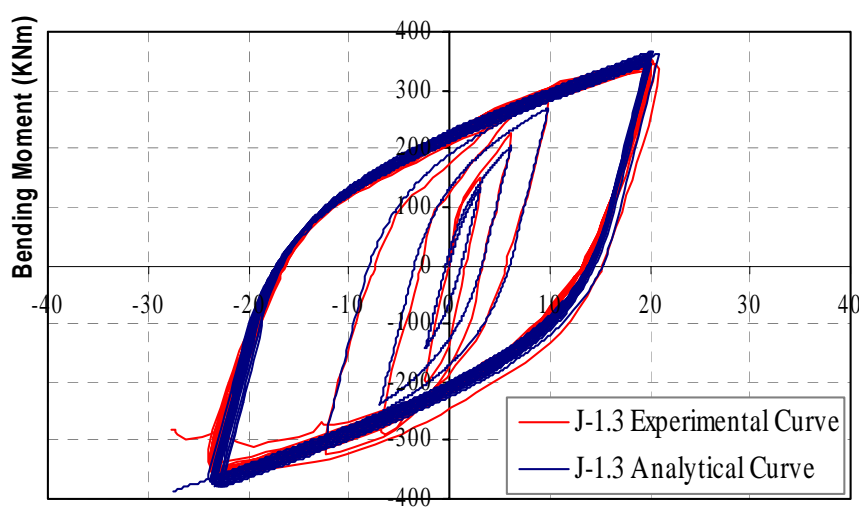

Rot. (mrad)

Figure 6: Experimental and analytical hysteretic curves; (a) J-1.2 test and (b) J-1.3 test. 
To assess the accuracy of the analytical model, the dissipated energy in each cycle from the experimental tests and the Modified Richard-Abbott model were evaluated. These results are graphically presented from Figures $7 \mathrm{a}$ to $8 \mathrm{~b}$ for $\mathrm{J}-1.2$ test and in figure 9 for $\mathrm{J}-1.3$ test. The percentage of error in each cycle was also evaluated and the results obtained are presented in all the graphs. It can be noticed that, the errors are small, in the range of $10 \%$ for the first test and in the range of $5 \%$ in the second one, except for the first cycles where the values of hysteretic energy dissipated are small.
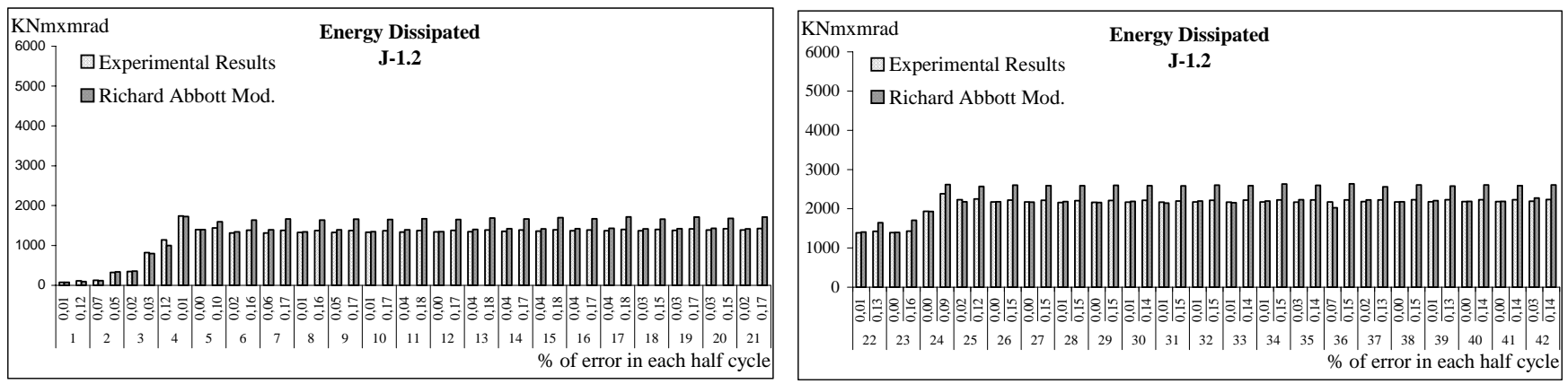

Figure 7: Energy dissipated in the joint J-1.2; (a) 1 o 21 cycles and (b) 22 to 42 cycles.
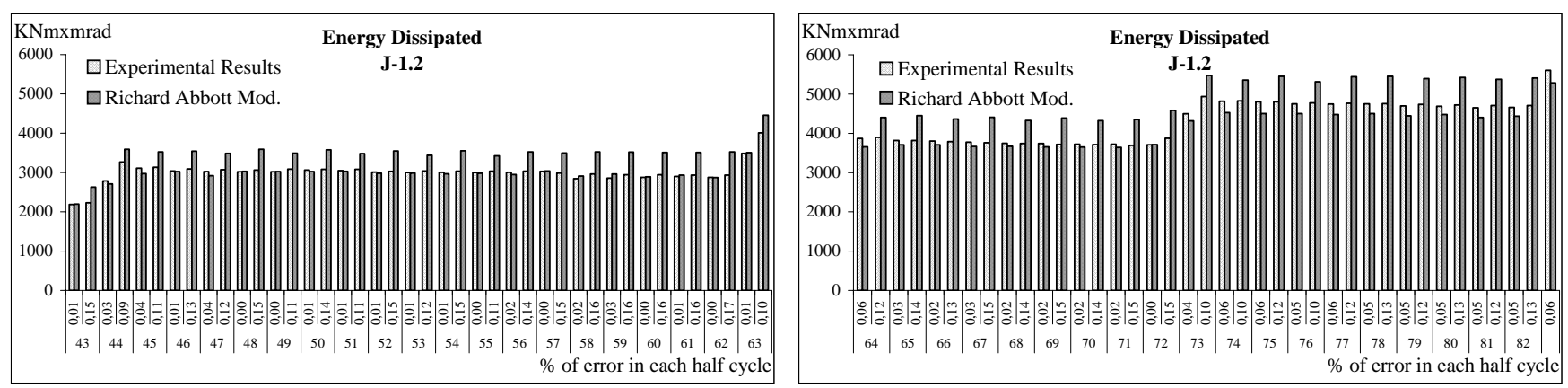

Figure 8: Energy dissipated in the joint J-1.2; (a) 43 to 63 cycles and (b) 64 to 82 cycles.

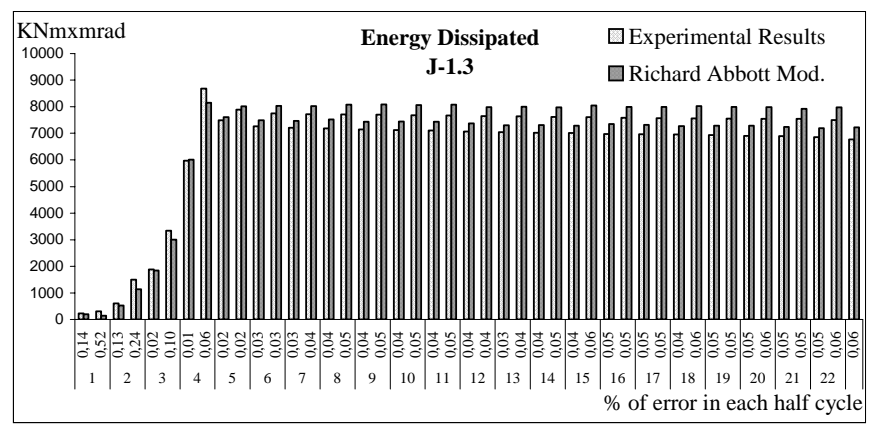

Figure 9: Energy dissipated in the joint J-1.3.

Figures 10a and 10b present the experimental and analytical $M-\phi$ hysteretic curves respectively for J-3.2 and J-3.3 tests. To find the joint parameters, the same considerations can be made. The mechanical properties observed in the monotonic J-3.1 test are again taken as the starting point.

Once again it can be observed the both curves and confirm the good agreement between them, except in the last cycle for the J-3.3 test, because in reality this cycle was made already, with large failure in the beam flange, which represents a significant deterioration of strength.

The dissipated energy in each cycle from the experimental tests and the Modified Richard-Abbott model were evaluated, again, as can be observed in the figure 11a and 11b. The results show errors approximately equal to $5 \%$, which means the the numerical results obtained are very close to the experimental ones.

In table 3 is presented the global cyclic joint characterization, defining the total number of cycles per each test, the respectively total energy hysteretic dissipated, experimental and analytical, and finally the 
percentage of error obtained. It can be concluded that, even when it is compared these global values, the observed errors are small.
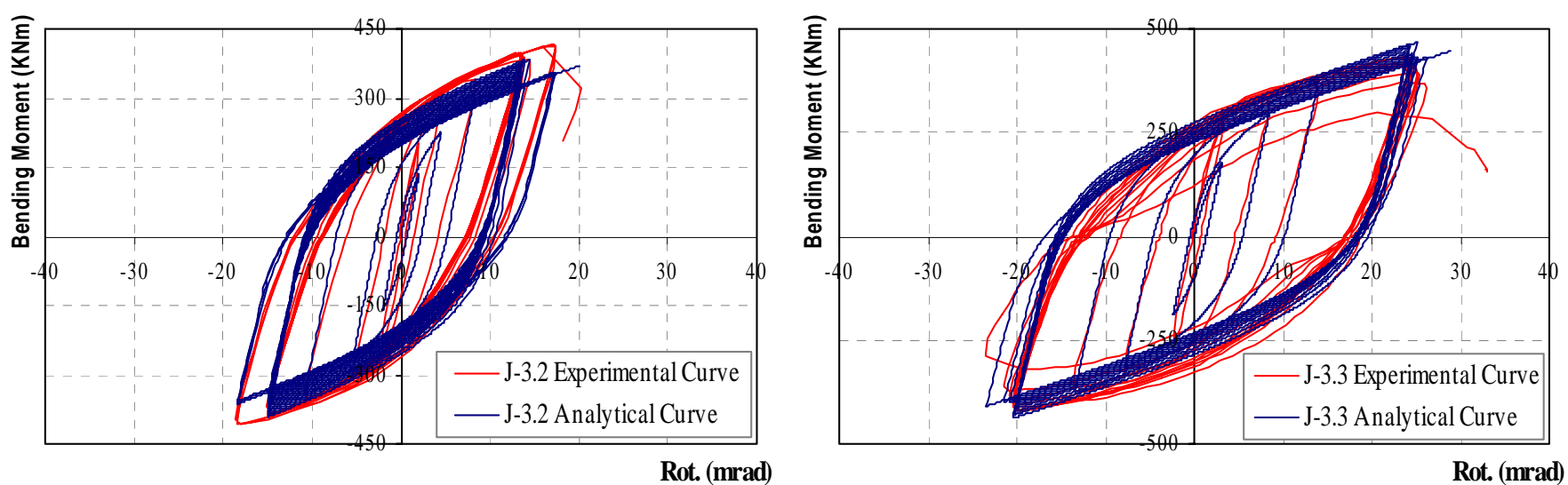

Figure 10: Experimental and analytical hysteretic curves; (a) J-3.2 test and (b) J-3.3 test.
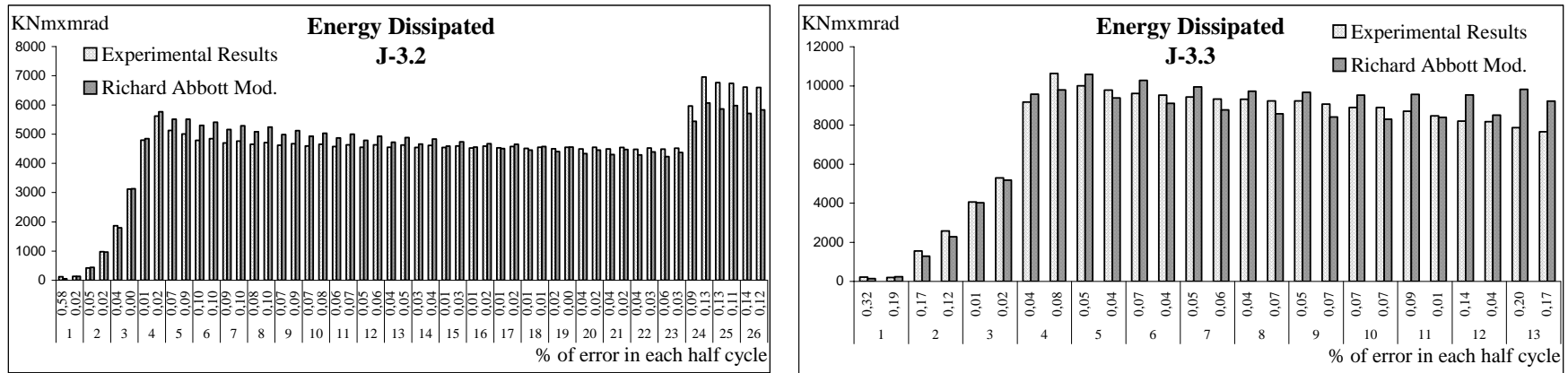

Figure 11: Energy dissipated; (a) J-3.2 test and (b) J-3.3 test.

Table 3: Global cyclic joint characterization.

\begin{tabular}{rcccc}
\hline Test & Cycles & $\begin{array}{r}\text { Total Hysteretic Energy dissipated (KNm·mrad) } \\
\text { Experimental }\end{array}$ & Analytical & $\begin{array}{c}\text { Error } \\
\text { (\%) }\end{array}$ \\
\hline J-1.2 & 82 & 435156 & 465902 & 7 \\
J-1.3 & 22 & 293979 & 305166 & 4 \\
J-3.2 & 26 & 232073 & 233824 & 1 \\
J-3.3 & 13 & 195075 & 199807 & 2 \\
\hline
\end{tabular}

After this calibration, the model is ready to be implement and used in the numerical software SeismoStruct [18], which means that the respectively steel structure can be analysed. In figure 12a can be seen a screenshot of one windows of the SeismoStruct software where the presented model was implemented. It is a numerical software which allows the non-linear seismic study of steel. In figure $12 \mathrm{~b}$ is presented an example of the hysteretic joint response for one structure with joints weaker than these ones studied. This joint was the one chosen to model the structure shown in the figure 12a, which was subjected to a seismic action simulated by means of an artificial accelerogram. 

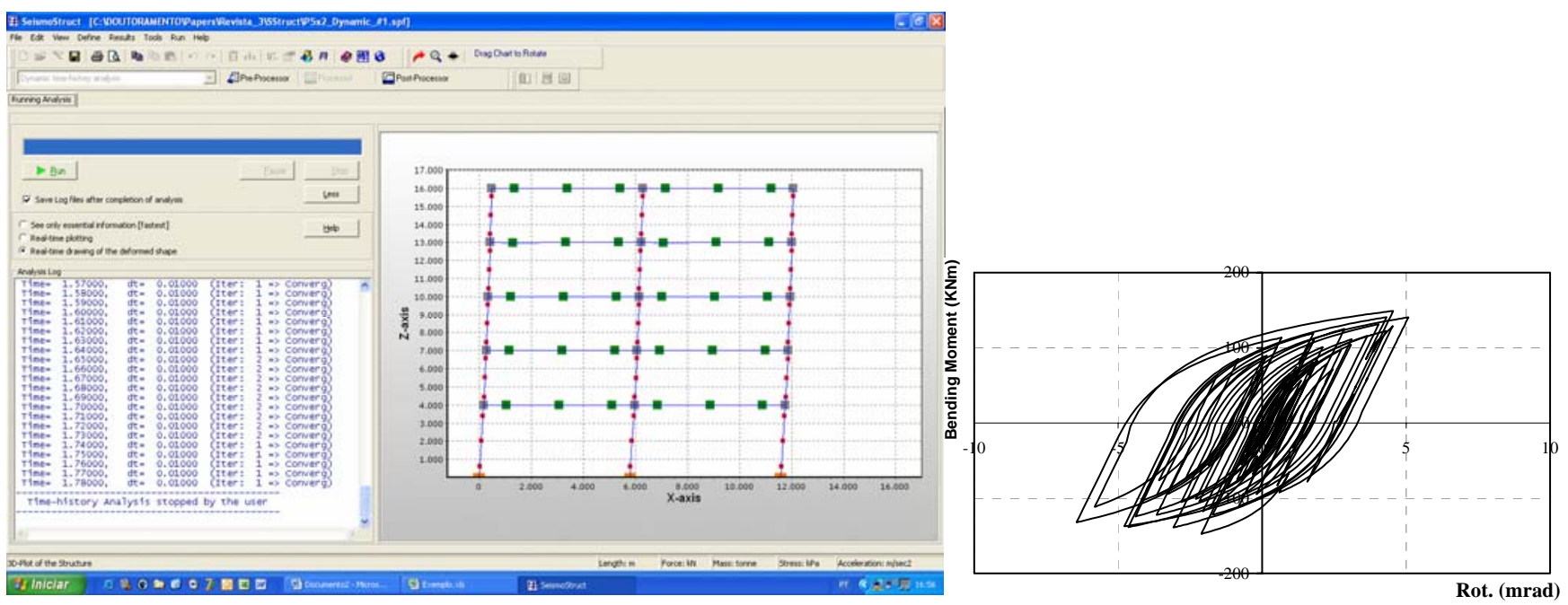

Figure 12: Implementation in the SeismoStruct; (a) Illustration and (b) One hysteretic joint curve.

\section{CONCLUSIONS}

The results of six experimental tests on external steel joints, divided in two main groups, was briefly presented. After the analytical description of the Modified Richard Abbott model, the paper presents the numerical implementation and calibration of the model for hysteretic cyclic response. The results obtained demonstrated the high performance of the model to simulate the real joint cyclic behaviour, which can represents an important tool to study numerically the steel structures when they are subjected to seismic actions.

Addtionally, it was possible to stablish representative values for the relevant parameters for the joint configurations. These parameters provide a reasonable basis for the analytical prediction of the symectric end-plate beam-to-column steel joints under arbitrary cyclic loading.

\section{Acknowledgements}

Financial support from the Portuguese Ministry of Science, Technology and Higher Education (Ministério da Ciência, Tecnologia e Ensino Superior) under contract grants from PRODEP III (5.3), for Pedro Nogueiro, Foundation of Science and Technology through POCI/ECM/55783/2004 and FEDER through INTERREG-III-A (project RTCT-B-Z-/SP2.P18) is gratefully acknowledged. The assistance provided by Seismosoft, is also most appreciated (http://www.seismosoft.com).

\section{REFERENCES}

1. EN 1998-1, Eurocode 8. Design of Structures for Earthquake resistance. Part 1: General rules, seismic actions and rules for buildings. Commission of the European Communities, Brussels, 2005.

2. FEMA Federal Emergency Management Agency. Program to Reduce the Earthquake Hazards of Steel Moment Frame Structures. Seismic Evaluation and Upgrade Criteria for Existing Welded Moment Resisting Steel Frame Construction. Sacramento, California, 1999.

3. SAC Joint Venture. Protocol for fabrication, inspection, tenting and documentation of beam-column connection tests and other experimental specimens. Rep. No. SAC/BD-97/02, Sacramento, Calif, 1997.

4. Ramberg, W. and Osgood, W.R. "Description of stress-strain curves by three parameters". Monograph N. ${ }^{\circ}$, Publicazione Italsider, Nuova Italsider, Genova, 1943.

5. Richard, R.M. and Abbott, B.J. Versatile Elasto-Plastic Stress-Strain Formula. Journal of the Engineering Mechanics Division, ASCE 101, EM4, 1975, 511-515.

6. Popov, E.P. and Pinkey, R.B. Cyclic loading of steel beams and connections subjected to inelastic strain reversals. Bull N. ${ }^{\circ}$ 3, (Nov.), American Iron And Steel Institute, Washington, D.C. 1968. 
7. Popov, E.P. and Bertero, V.V. Cyclic loading of steel beams and connections. Journal Struct. Div., ASCE, 99(6), 1973, 1189-1204.

8. Mazzolani, F.M. Mathematical model for semi-rigid joints under cyclic loads. In R. Bjorhovde et al. (eds) Connections in Steel Structurs: Behaviour, Strength and Design, Elsevier Applied Science Publishers, London, 1988, 112-120.

9. Simões, R., Simões da Silva, L. and Cruz, P. Cyclic behaviour of end-plate beam-to-column composite joints. International Journal of Steel and Composite Structures 1(3), 2001, 355-376.

10. De Martino, A., Faella, C. and Mazzolani, F.M. Simulation of Beam-to-Column Joint Behaviour under Cyclic Loads. Construzioni Metalliche 6, 1984, 346-356.

11. Della Corte, G., De Matteis, G. and Landolfo, R. Influence of Connection Modelling on Seismic Response of Moment Resisting Steel Frames. In: Mazzolani F.M., (ed.). Moment resistant connections of steel buildings frames in seismic areas, E. \& F.N. Spon, London, 2000, 485-512.

12. EN 1990, Eurocode. Basis of Structural Design. Commission of the European Communities, Brussels, 2005.

13. EN 1991-1-1, Eurocode 1. Actions on Structures - Part 1-1: General Actions - Densities, Selft weight, imposed loads for buildings. Commission of the European Communities, Brussels, 2005.

14. EN 1993-1-8, Eurocode 3. Design of steel structures - Part 1.8: Design of Joints. Commission of the European Communities, Brussels, 2005.

15. EN 1994, Eurocode 4. Design of composite steel and concrete structures. Part 1.1: General rules and rules for buildings. Commission of the European Communities, Brussels, 2005.

16. Nogueiro, P., Simões da Silva, L. and Bento, R. Numerical Implementation and Calibration of a Hysteretic Model with Pinching for the Cyclic Response of Steel Joints. Advanced Steel Construction. (to be published).

17. Delphi 7.Borland Software Corporation, 2002.

18. SeismoStruct. "Computer program for static and dynamic nonlinear analysis of framed structures" [online], 2004. Available from URL: http://www.seismosoft.com 